\title{
Políticas públicas en torno a los ex Centros Clandestinos de Detención Tortura y Extermino de Argentina: aproximaciones a partir de un estudio de caso
}

\begin{abstract}
Resumen
La meta de este artículo es reconstruir el conflictivo proceso de transformación del ex Centro Clandestino de Detención Tortura y Exterminio Campo de la Ribera en un Espacio para la Memoria, Promoción y Defensa de los Derechos Humanos, entre los años inmediatamente anteriores al retorno de la democracia en 1983 y su apertura al público en 2010. Con este propósito se retoman las políticas públicas e iniciativas de actores nacionales, provinciales y locales que intervinieron para imponer en el sitio determinadas representaciones del pasado y prácticas conmemorativas específicas. La investigación muestra el proceso de lucha social, política y simbólica de constitución de los espacios de memoria en los mismos lugares que se produjo la violación sistemática de derechos humanos, las dificultades de nombrarlos y reconocerlos como tales y la importancia del espacio como anclaje y soporte material de las disputas por el sentido del pasado reciente.
\end{abstract}

Palabras clave: Centro Clandestino de Detención, Tortura y Exterminio Campo de la Ribera. Políticas Públicas. Espacios de Memoria. Procesos de Resignificación. Memoria Social.

\author{
Vanesa Garbero \\ Doctora en Ciencias Sociales por la \\ Universidad de Buenos Aires (UBA). \\ Profesora del Centro de Estudios \\ Avanzados (Facultad de Ciencias Sociales, \\ Universidad Nacional de Córdoba) \\ Becaria postdoctoral del Consejo Nacional \\ de Investigaciones Científicas y Técnicas. \\ Córdoba - ARGENTINA \\ vanegarbero@yahoo.com.ar \\ orcid.org/0000-0001-8774-9353
}

\section{Para citar este artículo:}

GARBERO, Vanesa. Políticas públicas en torno a los ex Centros Clandestinos de Detención Tortura y Extermino de Argentina: aproximaciones a partir de un estudio de caso. Tempo e Argumento, Florianópolis, v. 11, n. 27, p. 43 - 77, maio/ago. 2019. 
Public politics around the former Clandestine Detention, Torture, and Extermination Centres of Argentina: approach from a case study

\begin{abstract}
The goal of this article is to reconstruct the conflictive transformation process of the former Detention, Torture and Extermination Clandestine Center Campo de la Ribera into a Site of Memory, Promotion and Defense of Human Rights, from the years immediately preceding the return of democracy in 1983 until its opening to the public in 2010. To this purpose, public policies and national, provincial and local initiatives that mediated to impose past representations as well as site specific commemorative practices were analized. The research shows the process of social, political and symbolic efforts during the conformation of the sites of memory at the same places that the systematic violation of human rights occurred, the difficulties of naming and recognizing them as such, and the importance of physical space as an anchor and material support for the struggles over the meaning of the recent past.
\end{abstract}

Keywords: Clandestine Detention, Torture and Extermination Center. Campo de la Ribera. Public Politics. Site of Memory. Resignification Processes. Social Memory.

\section{Políticas públicas em torno dos ex-Centros Clandestinos de Detenção, Tortura e Extermínio da Argentina: aproximações a partir de um estudo de caso}

\begin{abstract}
O objetivo deste artigo é reconstruir o conflitivo processo de transformação do ex- Centro Clandestino de Detenção, Tortura e Extermínio Campo de la Ribera em um Espaço para a Memória, Promoção e Defesa dos Direitos Humanos, desde os anos imediatamente anteriores ao retorno da democracia em 1983 até sua abertura ao público em 2010. Com este propósito são retomadas as políticas públicas e iniciativas de atores nacionais, provinciais e locais que intervieram para impor no lugar em questão determinadas representações do passado e práticas comemorativas específicas. A pesquisa mostra o processo de luta social, política e simbólica de constituição dos espaços de memória nos mesmos lugares em que se produziu a violação sistemática dos direitos humanos, as dificuldades de nomeá-los e reconhecê-los como tais e a importância do espaço como ancoradouro e suporte material das disputas pelo sentido do passado recente.
\end{abstract}

Keywords: Centro Clandestino de Detenção, Tortura e Exterminio. Campo de la Ribera. Políticas Públicas. Espaços de Memória. Processos de Ressignificação. Memória Social. 
El presupuesto material indispensable al sistema de desaparición forzada de personas perpetrado por el terrorismo de Estado en Argentina lo constituyeron medio millar de centros clandestinos de detención (CCD) distribuidos en todo el país. ${ }^{1}$ Los detenidos-desaparecidos confinados en los CCD eran sometidas a condiciones extremas de detención que incluían interrogatorios bajo tortura física y psicológica, vejaciones, aislamiento, escases de comida y agua y diversos mecanismos de deshumanización. Muchos de ellos estuvieron secuestrados durante días, meses e, incluso, en la mayoría de los casos, hasta su muerte e inhumación clandestina.

Estas estructuras edilicias, donde se secuestraba, torturaba y asesinaban, fueron transformadas, mayoritariamente, para borrar las huellas de los delitos y, en democracia, volvieron a ser sede de las funciones que cumplían antes de la represión o adquirieron usos diversos como viviendas de uso familiar o de soldados, escuelas, entre otros. Un momento bisagra en relación a la necesidad de preservar esos lugares y comenzar a pensarlos como sitios de memoria fue, tal como lo señala Da Silva Catela (2014), la polémica que suscitó el decreto presidencial 8/98 del 6 de enero de este 1998, que proponía la demolición de los edificios de la Escuela de Mecánica de la Armada (ESMA) ex CCD más grande del país- para convertirlos en un lugar verde, público y símbolo de unión nacional. En diciembre de ese año, la sala II de la Cámara de Apelaciones en lo Contencioso Administrativo Federal hizo lugar a pedido de amparo que habían presentado familiares de detenidos-desaparecidos de ESMA y frenó la demolición. El fallo reconoció que "la demolición del edificio podría destruir pruebas valiosas para establecer el destino de los familiares" de desaparecidos y "el derecho de quienes no son familiares directos 'y de la comunidad toda, a conocer la verdad histórica', derecho que la destrucción del edificio podría afectar" (cit. por VERBITSKY, 1998, p. s/n).²

Hacia comienzos del año 2000, entre el gobierno nacional y los provinciales, comenzaron a nacer diálogos y propuestas conjuntas entre los estamentos del Estado y

\footnotetext{
1 Entre 1930 y 1983 la Argentina sufrió seis golpes de Estado, solo al último ocurrido entre 1976-1983 le corresponde la expresión "terrorismo de Estado". El terrorismo de Estado implicó la utilización del poder represivo del Estado y su aparato, despojando a los ciudadanos de todos sus derechos civiles y libertades públicas, anulando las garantías constitucionales y marginando al Poder Judicial (SERVETTO, 2004).

${ }^{2}$ Disponible en: www.pagina12.com.ar/1998/98-12/98-12-24/pagog.htm Consultado en junio de 2019.
} 
los organismos de derechos humanos para crear diversas agencias encargadas de llevar a cabo proyectos conmemorativos sobre el terrorismo de Estado y monumentos públicos que recordasen a los desaparecidos (DA SILVA CATELA, 2014; GUGLIELMUCCI, 2013;). ${ }^{3}$ Estas iniciativas tuvieron un nuevo punto de inflexión con la llegada de Néstor Kirchner a la presidencia de la nación (2003-2007). Varios autores (BESSE; ESCOLAR, 2012; DA SILVA CATELA, 2010; GUGLIELMUCCI, 2013; LVOVICH; BISQUET, 2008, entre otros) coinciden en señalar esa coyuntura como el momento en que se vuelven parte de la política de derechos humanos del propio Estado las reivindicaciones históricas de los organismos de derechos humanos en materia de Memoria, Verdad y Justicia con relación a los crímenes perpetrados por el terrorismo de Estado. ${ }^{4}$ Así, se desarrollaron un conjuntos de medidas e iniciativas desde los poderes Ejecutivo, Judicial y Legislativo y diversos actos de alto contenido simbólico que dieron lugar a una política de memoria sobre lo sucedido durante la última dictadura militar. Una de esas medidas fue la "recuperación" de los ex

\footnotetext{
3 Solis señala que "La sociogénesis contemporánea de la cuestión de los derechos humanos en Argentina remite a la construcción de una situación de injusticia delimitada, en principio, por el legado no resuelto de sus violaciones sistemáticas durante el Terrorismo de Estado de la última dictadura militar. (...) siendo la última etapa de la dictadura y la inmediata transición el período en el que se configuró públicamente el sentido histórico de la cuestión, entendido éste como la asociación entre un nombre (los organismos) y una voz (los reclamos por verdad y justicia), entramado en la retórica de los derechos humanos y, al mismo tiempo, convertido en una exigencia que trascendía al original grupo de represaliados, sus familiares y allegados para lograr las más amplias solidaridades" (2012, p. 307-308). Crenzel (2008) retoma los aportes de Markarian para señalar que los derechos humanos se fueron incorporando a la cultura política argentina durante la dictadura a partir del contacto y de las relaciones que establecieron las organizaciones nacionales con las redes trasnacionales de derechos humanos. Para una reconstrucción y análisis de la historia del movimiento de derechos humanos en Argentina en dictadura y transición puede consultarse Leis (1989), Jelin y Azcárate (1991), Jelin (1995), Sikkink (1996). Otros estudios destacaron las profundas diferencias que coexistían en el interior de esas agrupaciones y tensionaron la misma "unidad de un agente colectivo de por sí plural y multiforme" (ALONSO, 2013, p. 105). La nueva camada de investigadores evidenció que aquellos primeros estudios "traspusieron la realidad -o incluso parte de la realidad- de una zona específica como Buenos Aires a la Argentina en su conjunto" (ALONSO, 2015, p. 121) y argumentan a favor de una identificación de variaciones regionales en la constitución del actor colectivo (ALONSO, 2008). En este sentido, para una reconstrucción en clave historiográfica del proceso de conformación y consolidación de los organismos de defensa de los derechos humanos en Córdoba, a partir de un conjunto de cambios y permanencias hasta la década de los ochenta, puede consultarse a Solis (2014). Para conocer los itinerarios públicos de la cuestión de los derechos humanos (incluidas las demandas por justicia) en Córdoba desde 1989 hasta el escenario posterior a la crisis del 2001, atendiendo a los actores, las demandas, los repertorios de acción y los sentidos construidos, véase Solis (2012).

4 Para un examen de las políticas de verdad, justicia y memoria desplegadas en la Argentina desde la recuperación de la democracia en 1983 hasta 2012, ante las sistemáticas violaciones a los derechos humanos perpetradas por la dictadura militar puede verse Crenzel (2015). También, para un resumen de esas políticas desde 1983 y 2015 puede verse Zaldua, Torras, Hourcade, Blanchard y Griffa (2016).
} 
CCD y la reconversión en espacios de memoria. ${ }^{5}$ Como instituciones del Estado pasaron a establecer nuevas relaciones con distintos grupos de la sociedad civil, ocupan lugares centrales en la visibilización, la construcción y la transmisión de la memoria sobre el terrorismo de Estado, y llevan adelante propuestas con intenciones de intervenir ante violaciones de derechos humanos de diverso orden en el presente.

¿Cómo se imaginó constituir espacios para la memoria y la promoción de los derechos humanos en los ex Centros Clandestinos de Detención, Tortura y Exterminio (CCDTyE)? ¿Cómo fueron pensados estos sitios en las distintas coyunturas políticas? ¿Cómo se desarrolló el proceso político de (re)significación de estos sitios en Argentina y, de modo particular en la provincia de Córdoba? Este artículo de investigación buscará dar respuesta a esas preguntas a partir de un caso de estudio. Para ello, se propone reconstruir el conflictivo proceso de conformación del ex CCDTyE Campo de la Ribera como Espacio para la Memoria, Promoción y Defensa de los Derechos Humanos, desde los años inmediatamente anteriores al retorno de la democracia hasta su apertura al público. Interesa comprender la interrelación entre las políticas públicas vinculadas al pasado reciente y los usos que tuvo el ex CCDTyE, el largo proceso de (re)significación y la manera en que diversos actores desplegaron una lucha política y simbólica en el espacio público, y en ese lugar en particular, en pos de inscribir una memoria y, como tal, su visión del pasado.

Campo de la Ribera funcionó como CCDTyE y base operativa del autodenominado “Comando Libertadores de América” (CLA) a partir de diciembre de 1975 hasta junio de 1978 en las instalaciones de una vieja cárcel militar. ${ }^{6}$ Está ubicado en el sureste de la

\footnotetext{
${ }^{5}$ La categoría "recuperación" hace referencia al proceso de transformación de los ex CCD en espacios para la memoria y es utilizada, generalmente, por los entrevistados vinculados a organismos de derechos humanos. Fue incorporada en las políticas de la memoria aunque no son espacios que les hayan pertenecido en el pasado y suele implicar un conjunto de tareas como expropiar, rescatar, señalar, mostrar, resignificar, etc., sobre ello puede consultarse Feld (2011).

${ }^{6}$ Para comprender el funcionamiento como CCDTyE antes del golpe de Estado de 1976 es preciso señalar que la provincia de Córdoba fue un foco temprano de represión y terror. Con el golpe policial de febrero de 1974, la destitución de las autoridades elegidas democráticamente y las sucesivas intervenciones federales significaron el despliegue de la represión material y simbólica y la anulación del ciclo de protesta y movilización iniciado en 1969 con el Cordobazo. Hacia mediados de 1975 se configuró un nuevo modelo represivo fruto de la nacionalización del operativo independencia en Tucumán. En Córdoba, esto tuvo lugar con el recambio en la conducción de las fuerzas de seguridad y el accionar conjunto de oficiales del Destacamento de Inteligencia 141 General Héctor A. Iribarren y la División de Informaciones de la Policía
} 
ciudad de Córdoba (provincia de Córdoba, Argentina), a pocos metros del Cementerio San Vicente, otro lugar en el que el modo de operación del terrorismo de Estado dejó su marca, ya que allí se encontró una de las mayores fosas comunes relacionadas con la práctica de desaparición de personas (Olmo, 2005). Forma parte del entramado urbano de barrios y villas de emergencia que, desde entonces y hasta la actualidad, están densamente poblados. Se estima que por el ex centro clandestino de Campo de la Ribera pasaron más de cuatro mil personas secuestradas, de las cuales alrededor de 115 permanecen desaparecidas y más de seiscientas sobrevivieron. ${ }^{7}$ La historia del sitio entrelaza el paso de una cárcel militar (1945-1975 y 1978-1986), un CCDTyE (1975-1978), tres centros educativos (1990-2009) y un Espacio para la Memoria, Promoción y Defensa de los Derechos Humanos desde marzo 2010 hasta la actualidad.

La propuesta de análisis de este artículo se deriva de una investigación de mayor alcance en la que se utilizó una estrategia metodológica cualitativa. El caso ha sido seleccionado debido a su importancia en el sistema represivo provincial y su relevancia dentro de las políticas públicas de memoria y derechos humanos en la provincia de Córdoba. La técnica principal de recolección de datos fue la entrevista en profundidad. De allí que, entre marzo de 2012 y marzo de 2017, se realizaron entrevistas a vecinos/as que habitan en las inmediaciones del sitio de Campo de la Ribera -barrios Maldonado, Müller y Bajada San José-, a los/as trabajadores/as de ese espacio de memoria y a otras personas que estuvieron en otros momentos de la historia del lugar. Las entrevistas se complementaron con el examen de un conjunto de fuentes secundarias como las producciones audiovisuales relacionadas con Campo de la Ribera realizadas por el Archivo Provincial de la Memoria, por el espacio de memoria y por vecinos/jóvenes de los barrios estudiados. Además, se consultaron fuentes documentales, testimonios de sobrevivientes obrantes en archivos públicos, publicaciones periodísticas y

(D2) bajo la supervisión del Comando del Tercer Cuerpo de Ejército encabezado por Luciano Benjamín Menéndez, designado jefe de este cuerpo de Ejército el 3 de septiembre de 1975. Fue entonces que apareció públicamente el CLA, conformado por grupos de la policía, militares del ala derecha nacionalista y algunos civiles que actuaban arbitraria y clandestinamente con la venia del interventor Lacabanne. Una vez producido el golpe de Estado, el CLA se disolvió como tal para "insertarse inmediatamente en el nuevo sistema represivo organizado por las Fuerzas Armadas" (PAIARO, 2012, p. 27).

7 Galará, Área de investigación del Espacio para la Memoria Campo de la Ribera, Campo de la Ribera, octubre de 2013. Las entrevistas realizadas por la autora de este texto no están disponibles en un archivo de consulta pública. 
autobiográficas, prensa gráfica nacional, provincial y local, y material producido por los organismos de derechos humanos provinciales que guardaran relación con Campo de la Ribera. También, se tuvieron en cuenta los archivos fotográficos disponibles en el espacio de memoria. ${ }^{8}$

A continuación, la exposición sigue un criterio cronológico. El primer y segundo apartado plantean las modalidades de visibilización e inscripción de Campo de la Ribera en la arena pública desde el retorno de la democracia hasta el 2003. El tercer apartado, situado en el trigésimo aniversario del golpe militar, explica el desarrollo de una política de la memoria en la provincia de Córdoba y hace foco en las iniciativas que gravitan en torno a la reconversión de los ex CCDTyE como espacios de memoria. Finalmente, se expone la recuperación de Campo de la Ribera en particular.

\section{El ex CCDTyE Campo de la Ribera como prueba material para la Justicia}

A diferencia de otros CCDTyE que fueron identificados recién con los primeros testimonios de los sobrevivientes en la etapa final del régimen dictatorial y en los momentos iniciales del régimen democrático, Campo de la Ribera no fue un lugar ni oculto ni secreto. Hubo denuncias tempranas que lo sindicaban como centro clandestino de detención de presos políticos.

Con el incremento de los secuestros a partir de diciembre de 1975 y los actos terroristas del CLA se suscitaron protestas y denuncias que repercutieron en la prensa local. Como consecuencia tuvieron lugar los reclamos de la Asociación de Familiares de Desaparecidos y Detenidos por Razones Políticas y un ataque conjunto de las organizaciones del Ejército Revolucionario del Pueblo (ERP) -brazo armado del Partido Revolucionario de los Trabajadores (PRT)- y Montoneros, -organización armada de origen peronista- con la finalidad de liberar a los presos políticos. ${ }^{9}$ La clandestinidad del

\footnotetext{
${ }^{8}$ Las fuentes secundarias analizadas son de acceso público. Están en formato papel, CD o DVD en el Archivo Provincial de la Memoria y/o en el Espacio para Memoria, Promoción y Defensa de los Derechos Humanos de Campo de la Ribera. Del mismo modo, los archivos fotográficos son de acceso público, pero no está disponible en internet la colección completa, sino que su consulta debe ser personal en el sitio de memoria.

${ }^{9}$ Galará, Área de investigación del Espacio para la Memoria Campo de la Ribera, Campo de la Ribera, abril de 2015.
} 
lugar no estaba dada porque se desconociera su existencia, sino por las prácticas clandestinas e ilegales desenvueltas en su interior.

Quienes testimoniaron de modo fehaciente sobre el rol de Campo de la Ribera en el circuito clandestino de represión fueron los sobrevivientes que en algún momento de sus prolongados cautiverios fueron trasladados a ese sitio. En este sentido, los primeros testimonios situados entre 1979 y 1983 de sobrevivientes del ex CCDTyE La Perla denunciaron también la existencia de Campo de la Ribera y describieron su funcionamiento, aunque con menor detalle, ya que estuvieron allí por períodos de tiempo muy cortos. ${ }^{10}$ También, el testimonio escrito de Carlos Raimundo "Charlie" Moore en noviembre de 1980 para el Alto Comisionado de las Naciones Unidas para los Refugiados (ACNUR) en San Pablo (Brasil) es de suma relevancia porque aportó conocimiento novedoso sobre el surgimiento del CLA, su composición, sus acciones y los responsables y describió su funcionamiento en Campo La Ribera en diciembre de $1975 .{ }^{11}$

En otras publicaciones que circularon en el país y en el exterior en ese mismo período (C.A.D.H.U, 1980; CONTEPOMI y ASTELARRA, 1984; REYNA, 1984) también se denunció el temprano funcionamiento de Campo de la Ribera como base de operaciones del CLA, bajo la responsabilidad del Capitán Héctor Pedro Vergéz, alias Gastón o Vargas. De esas publicaciones se deduce que Campo de la Ribera tuvo una etapa de funcionamiento previa a la dictadura militar en la que se sitúan los fusilamientos grupales en el pasillo y patio de la vieja cárcel y el asesinato del soldado Giménez luego de ser brutalmente torturado -acusado de haber favorecido el asalto del Batallón 141 por parte del ERP en 1973 mientras cumplía el servicio militar-. Sobre este período, los testigos

\footnotetext{
${ }^{10}$ La Perla fue, después de la Escuela de Mecánica de la Armada (ESMA) y Campo de Mayo, el tercer centro clandestino más grande de la Argentina y desde donde se organizó la actividad represiva ilegal de toda la provincia. Está ubicado en la ruta $\mathrm{N}^{\circ} 20$ que une Córdoba con Villa Carlos Paz, a la altura del puente que lleva a la localidad de Malagueño. Su funcionamiento como centro clandestino data de marzo de 1976 hasta fines de diciembre de 1978. Tello precisa que estos primeros testimonios sobre La Perla se sitúan temporalmente entre 1979 y 1980, los elaborados en el exterior fueron publicados entre 1979 y 1982, mientras que los testimonios en Argentina recién aparecen durante los primeros meses de democracia (2015, p. 96).

${ }^{11}$ Carlos Raimundo "Charlie" Moore era integrante del ERP, fue secuestrado el 13 de noviembre de 1974 por la "patota" del D2 durante seis años y fue "testigo" de las acciones policiales, circulando por diferentes CCD y cárceles (Catela Da Silva en ROBLES, 2010). Se fugó a Brasil, el 12 de noviembre de 1980. Moore estuvo en dos momentos cortos en La Ribera, en noviembre de 1976 y en septiembre de 1977 (ROBLES, 2010).
} 
tomaron conocimiento a partir de los relatos transmitidos por los mismos represores o gendarmes durante su cautiverio. ${ }^{12}$ Además, estas publicaciones aluden al rol derivador que cumplió Campo de la Ribera en tanto eran llevados detenidos de todo tipo a los que, una vez verificados los antecedentes, se los conducía a la cárcel, salían en libertad o ingresaban al ex CCDTyE La Perla. En otro momento, la circulación de los secuestrados fue primero La Perla, luego Campo de La Ribera, sea por uno o varios días, y de allí a otro centro clandestino, a la cárcel o la libertad condicional. También, los testimonios afirman que a principios de mayo de 1978, en vista a la visita de la comisión de la Cruz Roja Internacional que tendría lugar el año siguiente para recibir las denuncias por violaciones a los derechos humanos, el aparato que funcionaba en La Ribera fue trasladado al ex CCD La Perla Chica o "casa de Malagueño” (C.A.D.H.U, 1980). ${ }^{13}$

Con el regreso de la democracia en 1983, el presidente Raúl Ricardo Alfonsín anuló, por inconstitucional, la autoamnistía militar, y creó, el 15 de diciembre de ese año, la Comisión Nacional sobre la Desaparición de Personas (CONADEP), con el objetivo de “esclarecer los hechos relacionados con la desaparición de personas ocurridos en el país" (decreto presidencial 187/83). ${ }^{14}$ A partir de la solicitud de organismos de derechos humanos Córdoba se constituyó una delegación de la comisión nacional en esta provincia (resolución CONADEP con fecha del 16 de febrero de 1984), bajo la presidencia del arquitecto Luis Rébora. ${ }^{15}$

Los informes nacional y provincial de la CONADEP $(1984 ; 1999)$ dan cuenta de la lógica de represión sistemática y clandestina que rigió el funcionamiento del Campo de la Ribera, y la relación con otros centros clandestinos de Córdoba y del resto del país en el intercambio y traslado de prisioneros. El trabajo de la Comisión logró reunir los testimonios de sobrevivientes y testigos directos y pruebas documentales que fueron

\footnotetext{
${ }^{12}$ En el libro de los sobrevivientes Contepomi y Astelarra (1984, p. 21) hay una brevísima referencia a los enterramientos clandestinos el Cementerio San Vicente de las víctimas fusiladas en Campo de la Ribera.

13 La Perla Chica era una base militar anexa de La Perla, los testimonios de los sobrevivientes la señalan como CCD durante 1976-1979; cumplió un rol fundamental en alojar a los secuestrados durante el Mundial de Fútbol de 1978 y la visita de la Cruz Roja Internacional al país.

${ }^{14}$ Por "Autoamnistía" se conoce a la ley de "Pacificación Nacional" proclamada por la dictadura militar el 22 septiembre de 1983, un mes antes de los comicios, que declaraba extinguidas las causas penales por delitos cometidos durante la "lucha antisubversiva".

${ }^{15}$ Para conocer el funcionamiento de la CONADEP delegación Córdoba puede consultarse el testimonio de Luis Armando Rébora en Diario del Juicio, 20 de agosto de 1985, p. 292-296. También, el prologo del Informe CONADEP, delegación Córdoba (1999).
} 
elevadas a la justicia federal y permitió, entre otras cosas, esclarecer la denuncia sobre la muerte de Amelia Nélida Insaurralde -que fue retirada de la cárcel del Buen Pastor y trasladada a La Ribera, donde falleció a causa de las torturas y se la pretendió presentar como resultado de un suicidio-, lo cual motivó el procesamiento del Gral. Juan Bautista Sasiaiñ y probar el funcionamiento de Campo de la Ribera como centro clandestino de detención ya en diciembre de 1975. Además, la investigación practicada por la Comisión permitió corroborar ciertos aspectos del funcionamiento del CCD e identificar a algunos de los responsables a partir de las declaraciones de los gendarmes Carlos Beltrán y José María Domínguez:

Nos enviaban a La Ribera por períodos de veinte días aproximadamente, siempre acompañados por oficiales de Gendarmería... Estuve allí seis veces y pude observar a unos treinta detenidos, hombres y mujeres, alojados en una cuadra. Todos los días venían miembros de Inteligencia del Batallón 141, cuando lo hacían por la noche, generalmente traían 'paquetes', como se denominaba comúnmente a los detenidos. Cuando los llevaban a interrogar a veces nos ordenaban que los 'ablandásemos', lo cual consistía en someterlos a duros castigos en un terreno ubicado en las proximidades del río (testimonio del gendarme Carlos Beltrán. CONADEP, 1984, p. 201).

Existía una habitación para los interrogatorios. Ahí pude ver cómo se torturó a los detenidos, sumergiéndolos en un tambor con agua. Entre los interrogadores recuerdo a 'H.B.', 'Gino', 'Vargas' y 'Fogo'"' (Gendarme José María Domínguez. CONADEP, 1984, p. 201).

La CONADEP junto a un grupo de sobrevivientes realizó un reconocimiento ocular de las instalaciones de Campo de la Ribera confirmando cada uno de los sitios descriptos con anterioridad por los testigos, quienes también pudieron dar cuenta de las modificaciones edilicias efectuadas. En ese momento, el sitio estaba siendo utilizado para fines militares, había vuelto a funcionar como Prisión Militar de Encausados Córdoba desde 1978 y tendría ese destino hasta 1986 cuando el precio queda abandonado. En este sentido, el reconocimiento de este y estos sitios realizados por la CONADEP fueron valiosos en tanto la "construcción de pruebas" para la justicia -no estaban dadas las condiciones para pensar en otro destino-. En esa visita, se tomaron fotografías que de alguna manera objetivaron las memorias de los sobrevivientes y que en la actualidad, luego de las importantes modificaciones operadas sobre el edificio, adquieren un valor documental fundamental. 

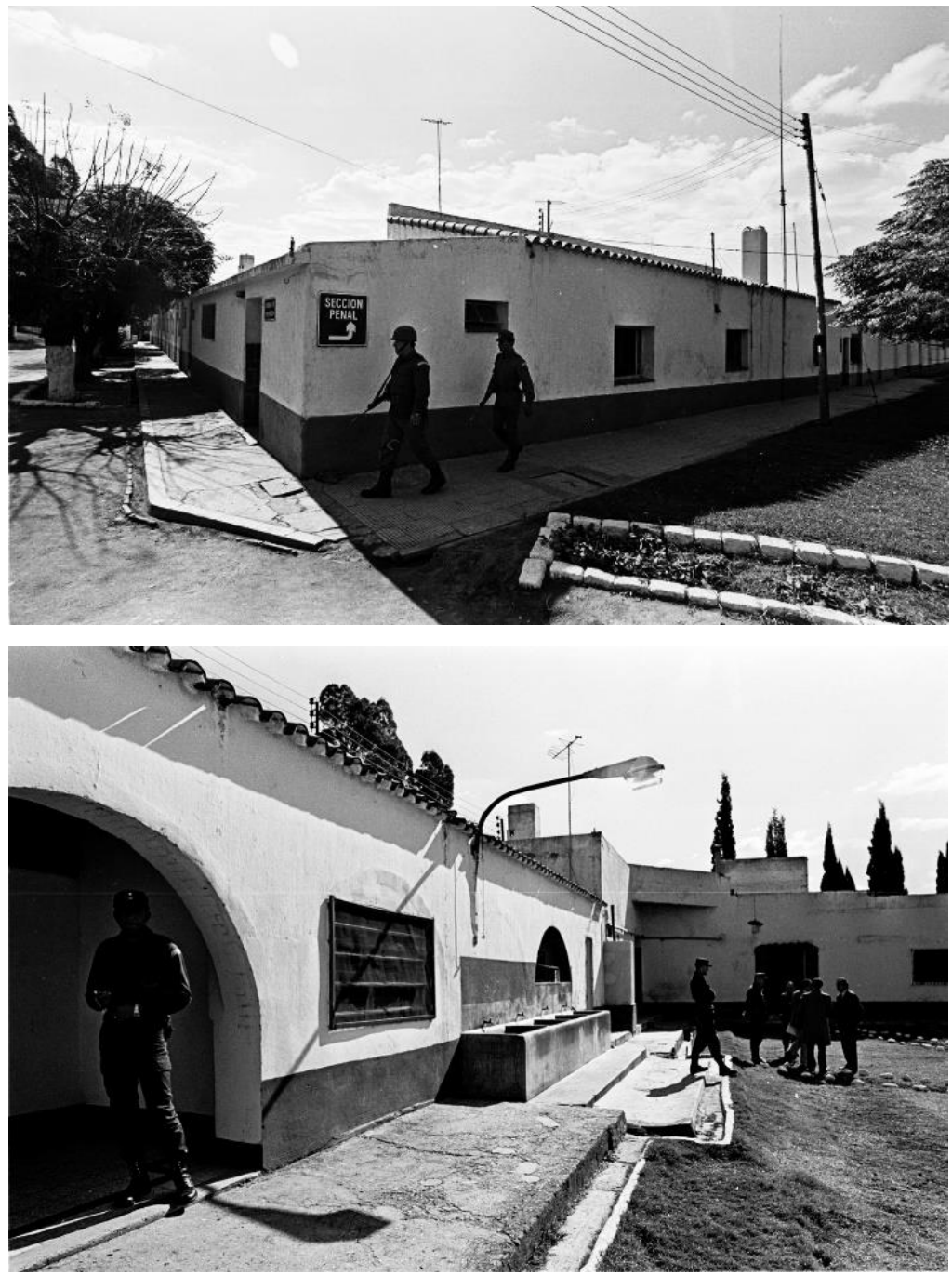

Imagen 1 y 2: Fotografías de la colección Campo de la Ribera, Archivo CONADEP, 1984.

Fuente: Espacio para la Memoria, Promoción y Defensa de los Derechos Humanos Campo de la Ribera.

También por medio del trabajo de investigación de la CONADEP se tomó conocimiento de enterramientos clandestinos de un elevado número de cuerpos sin identificación en fosas comunes en el Cementerio San Vicente y la Justicia Federal de Córdoba ordenó las excavaciones en un sector del Cementerio que posibilitó los hallazgos de numerosos restos óseos y la identificación de aquellos correspondientes a una joven. ${ }^{16}$

El material probatorio producido por la Delegación constituyó un elemento importante para comenzar a desarrollar las causas judiciales que tuvieron lugar en ese momento y también, a partir de 2005 cuando se reabrieron las causas en Córdoba. La narrativa del informe Nunca Más constituyó aquello que Crenzel denominó un nuevo

\footnotetext{
${ }^{16}$ Sobre las inhumaciones y las exhumaciones en el Cementerio San Vicente en 1984 véase Crenzel (2005).
} 
"régimen de memoria" que "integró ciertos principios generales de la democracia política, los postulados del gobierno de Alfonsín para juzgar la violencia política y la narrativa humanitaria forjada durante la dictadura para denunciar sus crímenes" (2008, p. 24). El autor demostró que el informe “derrumbó en la esfera pública el monopolio de la interpretación ejercido hasta entonces por las Fuerzas Armadas sobre los desaparecidos, al comprobar la existencia de un sistema clandestino de alcance nacional, bajo la responsabilidad de las Fuerzas Armadas, que perpetró este crimen" (CRENZEL, 2015, p. $55) \cdot{ }^{17}$

Otra medida que tomó el presidente Alfonsín ni bien asumió el gobierno fue el juicio oral y público a las Juntas militares (decreto 158/83) y a siete jefes guerrilleros del “ERP” y de la organización “Montoneros" (decreto 157/83) por actos de violencia cometidos desde 1973. "Esta disposición fue denominada la 'teoría de los dos demonios' pues limitaba a dos actores la responsabilidad por la violencia política y postulaba a la violencia de Estado como respuesta a la guerrilla" (CRENZEL, 2015, p. 56-57).

Este juicio comenzó el 22 de abril de 1985 y se extendió casi por ocho meses, a lo largo de los cuales declararon 833 personas, entre ellas ex detenidos desaparecidos, familiares de las víctimas, personal de las Fuerzas Armadas (FF.AA), entre otros. En Córdoba se conformó una gran causa denominada 'Causa 31-M-87', la cual "se constituyó en la causa madre de todos los juicios posteriores (...) Dicho expediente estaba constituido por más de 350 causas que implicaban un total de más de 900 casos individuales que reflejaban los circuitos del aparato represivo de la provincia" (BONAFÉ; DI TOFFINO, 2013, p. 7-8).

En términos generales, en el Juicio a la Juntas Campo de la Ribera se inscribió como un campo de menor envergadura represiva que La Perla y con un rol "derivador" o de paso en la red clandestina de represión de numerosos presos/secuestrados con distintas trayectorias incluso algunos no procedían de la política ni de la militancia social ni gremial. Los testimonios establecen, de hecho, una jerarquía entre Campo de la Ribera y La Perla:

\footnotetext{
17 Para un análisis de los procesos políticos, discursivos, culturales y materiales de la producción, circulación y recepción del Nunca Más, informe de la CONADEP, puede verse el trabajo de Crenzel (2008).
} 
El campo de la Ribera también era un campo de detención, pero que tenías otras características distintas de las de La Perla. En la terminología de los militares La Perla era la universidad, porque de allá el destino final era El Pozo, y en cambio La Escuelita, que era La Ribera, ellos lo utilizaban como un lugar transitorio para que después legalizar a las personas enviándolas a la cárcel. En esos días antes de salir creo que nos liberaron; nos trasladaron a La Ribera, a Piero Di Monti y a Liliana Callizo (Testimonio de Cecilia Suzzara, Diario del Juicio,1985, p. 267) ${ }^{18}$

La lucha contra la subversión se hizo primero con el procedimiento de secuestro de personas a través de grupos militares o paramilitares (...); después de eso, el secuestro en centros clandestinos de detención, donde la tortura fue el método permanente para todos los detenidos e inclusive en muchos casos, no podría precisar el porcentaje, la ejecución sin juicio de ningún tipo, sin que el detenido tenga la menor posibilidad de defensa. Eso fue sintéticamente lo que nosotros pudimos constatar en La Perla y en La Ribera. Lo que sí podemos afirmar, es que el régimen de La Ribera fue menos severo que el régimen de La Perla, donde fueron muy pocos los que pudieron salir e informar sobre estos hechos (...) (Testimonio de Luis Armando Rébora, Diario del Juicio, 1985, p. 293).

El Juicio a las Juntas Militares demostró de modo indudable el carácter sistemático de la represión, el exterminio bajo la responsabilidad del Estado, y si bien la sentencia acotó la condena a los jefes de cada arma -desestimando el pedido de la fiscalía de afectar a los integrantes de cada una de las tres juntas-, también colocaba en cuestión la obediencia debida e instaba al Consejo Supremo de las FF.AA. a llevar a cabo investigaciones que permitieran establecer responsabilidad de los jefes de zona y subzona en las acciones represivas (LVOVICH y BISQUET, 2008). Debido a la agudización de la presión militar para que finalizaran las investigaciones y los juicios, la libertad de los jueces se vió acotada tras la aprobación en diciembre 1986 de la Ley de Punto Final (23.492) porque establecía un plazo para la presentación de denuncias por desaparición de personas y el avance de las causas judiciales.

En Córdoba, el descontento de las FF.AA. desembocó en abril de 1987 en el auto acuartelamiento en el Tercer Cuerpo de Ejército del Mayor Ernesto Barreiro, uno de los principales responsables del CCDTyE La Perla, tras negarse a comparecer ante los tribunales federales y transformó su demanda en un postulado de todos los sectores militares implicados en las violaciones a los derechos humanos (BONAFÉ y DI TOFFINO, 2013, p. 11). En apoyo a Barreiro, ese mismo día se produjo la "rebelión Carapintada" de

\footnotetext{
${ }^{18}$ El pozo refiere a los fusilamientos y a los entierros de cuerpos en fosas comunes.
} 
Semana Santa, dirigida por el Teniente Coronel Aldo Rico, con la toma de la Escuela de Infantería de Campo de Mayo. Finalmente, el levantamiento dio lugar, ese mismo año, a la sanción por parte del gobierno de Alfonsín de la ley de Obediencia Debida ( $\left.\mathrm{N}^{\circ} 23.521\right)$, la cual eximió de responsabilidad penal a quienes se entendía habían actuado cumpliendo órdenes. ${ }^{19}$ Cuando Carlos Menem asumió la presidencia en 1989 y anunció su intención de "reconciliar" y "pacificar" a la sociedad. En ese sentido firmó el indulto a casi trescientos militares y guerrilleros (decretos 1002/89, 1003/89, 1004/89 y 1005/89). Luego, en 1990 tras un nuevo levantamiento militar, el 29 y 30 de diciembre de 1990, Menem firmó nuevos indultos, esta vez para los miembros de las Juntas militares condenados en 1985 y a otros militares condenados, al líder de la organización Montoneros, Mario Firmenich, al ex ministro de Economía Martínez de Hoz y a Norma Bremilda Kennedy y Duilio Antonio Brunello procesados y condenados por malversación de fondos públicos (decretos 2741/90, 2742/90, 2743/90, 2744/90, 2745/90). Con ello se dieron por concluidos los procesos legales.

\section{En tiempos de impunidad: el traslado de instituciones educativas a las instalaciones de Campo de la Ribera}

En un contexto nacional caracterizado por la suspensión de los procesos judiciales, el otorgamiento de indultos y la propuesta de reconciliación y olvido, el gobernador de la provincia de Córdoba, Eduardo Angeloz, gestionó en 1989 ante la Nación la compra del terreno de Campo de la Ribera al Ejército, para instalar allí la Escuela Primaria Canónigo Piñero. ${ }^{20}$ Esta escuela funcionaba en las instalaciones pequeñas y en paupérrimas

\footnotetext{
${ }^{19}$ Según Jelin y Azcárate, "La política de derechos humanos de Alfonsín adoptó un "conjunto de principios y demandas del movimiento [de derechos humanos], pero no todas ni de manera cabal" (1991, p. 32). Estos autores señalan que esta política de derechos humanos relacionada con los crímenes cometidos por el terrorismo de Estado tuvo dos caras: por un lado incluyó medidas "como la reforma del código de justicia militar, el decreto de juicios sumarios y la creación de al CONADEP". Por otro, la que "respondía a la necesidad de limitar la persecución judicial" y negociar con el actor militar. En esta segunda línea "deben entenderse las Instrucciones al Fiscal Militar, la ley de Punto Final y la Ley de Obediencia Debida" (1991, p. 33).

20 "El 22 de mayo de 1990 se firmó la escritura de compra del predio -con los mismos límites de la primera transacción- por la Provincia de Córdoba; la misma es firmada por el Coronel Lindor Aurelio Martín en representación del Estado Nacional y por Luis Arturo Ramón Molinari por la Provincia. Se abona la suma de 506.242.680 australes". Información brindada a la autora por Delia Galará, trabajadora del área de Investigación del Espacio para la Memoria de Campo de La Ribera.
} 
condiciones de la Parroquia de la Bajada San José, ubicada a pocas cuadras de Campo de la Ribera. Los padres de los alumnos y los directivos de la institución venían solicitando al Estado provincial que les concedieran un edificio nuevo en terrenos cercanos.

En 1990 se efectivizó el traslado de la escuela primaria a uno de los edificios del predio de la Ribera, específicamente a lo que había sido la cuadra de soldados. Pocos meses después, también, se creó el Jardín de Infantes Canónigo Piñero y para su funcionamiento se edificó una construcción entre los dos edificios existentes en el predio (durante la época militar allí había solo una habitación). Y en mayo de 1991, por decreto provincial, se originó el Bachillerato Técnico Especializado en Construcciones y Técnicas Artesanales que comenzó a funcionar en un par de aulas cedidas por el nivel primario. ${ }^{21}$ En la tarjeta de inauguración del secundario, firmada por Eduardo Angeloz, decía “Donde antes estaba la muerte, hoy vamos a trabajar por la vida”. Sin embargo, la delegación Capital de la Unión de Educadores de la Provincia de Córdoba consideró que el traslado de la escuela a los predios de Campo de la Ribera "pretendía blanquear un lugar de matanza" (MARCHETTI y MOLAS Y MOLAS, 2004). Esta afirmación estaba en sintonía con los impactantes hallazgos de las fosas comunes -e incendio posterior de las bolsas que acopiaban los restos óseos- en el colindante Cementerio San Vicente en 1984 durante los mismos gobiernos provincial y municipal. Excepto el reclamo del sindicato docente, no hay registros de protestas ni denuncias por el establecimiento de las escuelas en un sitio con la historia de La Ribera, y el traslado sucedió sin mayores sobresaltos (MOLAS Y MOLAS, 2010). ${ }^{22}$ Esto puede deberse según los vecinos entrevistados de la zona -varios de ellos familiares directos de los estudiantes que cursaron sus estudios en el lugar-, a que el traslado de la escuela significó cierto alivio y un logro en cuanto a los reclamos y las condiciones anteriores. Para ellos, Campo de la Ribera era relativamente más seguro en relación al lugar que ocupaba la escuela en la Bajada San José, donde resultaban muy frecuentes y constantes los ataques y situaciones de inseguridad y violencia que padecían

\footnotetext{
${ }^{21}$ Decreto 871/91 y autorizado a funcionar desde el 13 de mayo de 1991, por resolución de la Dirección de Enseñanza Media $N^{\circ} 394 / 91$.

${ }^{22}$ Para sostener este dato Molas y Molas (2010:108) cita un trabajo del programa de posgrado Análisis Institucional de la Educación y sus instituciones (Universidad Nacional de Córdoba), realizado en los años 1990 por Alem, del Pino y Ezpeleta donde se aborda el momento de traslado de la escuela primera. El informe se denominó "Diagnóstico institucional de las escuela primaria y media que funcionan dentro del Campo de la Rivera”.
} 
las maestras y los alumnos. Sin embargo, los alrededores inmediatos de Campo de la Ribera estaban despoblados y las dimensiones y características del propio edificio no contribuían a generar un espacio apropiado para la enseñanza-aprendizaje. Estas condiciones morigeraban aquel "alivio" y "logro" y posicionaban a Campo de la Ribera, con cierta resignación ante la falta de alternativas mejores, como "el único lugar disponible" para instalar la escuela.

La matriculación estudiantil de nivel medio creció y no resultó viable continuar compartiendo el edificio con el nivel primario. A raíz de esto, a finales de 1991 la directora del nivel medio elaboró un informe en el cual destacó la necesidad de obtener edificios propios. La respuesta desde el Ministerio de Educación se limitó a transferirle a la institución la responsabilidad de hallar un lugar que posibilite la continuidad de su funcionamiento. Según el testimonio de una preceptora que estuvo desde que se inauguró allí el nivel secundario, se hicieron averiguaciones de las alternativas en la zona pero los resultados fueron negativos (testimonio de Marcela Quadarella, preceptora y docente del secundario, cit. en documental audiovisual de CRISTORI, GUEVARA, PONTILIANO, Y ABRAHAM, 2004). En función de ello la directora resolvió, en agosto de 1992, la ocupación del edificio donde había funcionado la cárcel del ex CCDTyE y el posterior aviso a las autoridades provinciales para que reacondicionaran el lugar (MOLAS Y MOLAS y LEMME, 2002). Las refacciones a cargo del gobierno provincial nunca se concretaron de forma completa y fueron los propios docentes, los alumnos y sus padres quienes realizaron el acondicionamiento inicial.

Según los entrevistados, el traslado de los alumnos del secundario a la vieja cárcel y el posterior acondicionamiento llevado a cabo por los docentes, padres y adolescentes generó en la comunidad cierta estima por el lugar. Como consecuencia no prevista significó uno de los puntapiés principales para que en los barrios se vuelva a hablar sobre la historia de La Ribera y a transmitir recuerdos relacionados. Así, lo rememoran diversos vecinos entrevistados: 
Bueno eso, eso fue lo que disparó un montón de cosas para mí, ¿no?... disparó un montón de cosas porque los chicos sacaron. $O$ sea lo que vivieron los chicos, la primera tanda de alumnos fue lo que salieron a decir, lo que ellos habían visto. Antes, una persona del barrio no tenía acceso a entrar ahí, los primeros que tuvieron acceso a entrar ahí fueron los chicos para ir reparando las aulas. Iban reparando una, una, una celda, por decirlo así, a una, un lugar (...) yo lo sé a eso porque estuvo, estuvieron dos hermanas mías estudiando ahí, acá en el primer este, grupo de egresados (GASTÓN, vecino de Müller, 54 años, promotor vecinal del Ministerio de Desarrollo Social, Müller, septiembre de 2012).

(...) empezaron a ver que eso había sido una cárcel donde habían tenido gente. $Y$ tuvo toda una historia que empezaron los mismos chicos, los mismos alumnos empezaron a investigar y empezaron a dar clases de eso (ALEJANDRA, vecina de Maldonado, 53 años, ama de casa y ocasionalmente costurera, Maldonado, agosto de 2013).

Fueron los alumnos quienes comenzaron a hablar con sus padres, familiares y amigos sobre sus primeros hallazgos en el proceso de transformar la prisión en una escuela y a traer a cuenta relatos que remitían al uso del lugar como centro clandestino (GARBERO, 2014). Según los entrevistados, los alumnos encontraron frases escritas por los prisioneros e impactos de balas en paredes y puertas. También, manifestaron que hallaron restos humanos (un dedo y una cabeza en oportunidades diferentes) y manchas de sangre en las paredes.

Entonces, para principios de los '90, mientras las decisiones políticas intentaban ocultar y olvidar la represión, en Campo de la Ribera los relatos de los alumnos, una generación que tal vez no compartía los silencios de los adultos en relación a la dictadura y a lo vivido como testigos del ex CCDTyE, reabrieron el tema en los barrios colindantes. De alguna forma, las historias transmitidas y recreadas por ellos ayudaron a reactualizar aquello sentido, escuchado y visto por los vecinos años antes.

Sin embargo, aun cuando los alumnos activaban ciertos relatos que remitían al pasado del lugar, la investigación de Molas y Molas (2000) demostró que el personal a cargo de la institución, al menos hasta el año 2003, fue reticente a tratar y reconstruir la historia del edificio; el pasado se configuró como molesto, inentendible, marginal y por lo tanto completamente silenciado. La hipótesis de la autora es que fue la negación del pasado del lugar lo que les permitió trabajar en la escuela (MOLAS Y MOLAS, 2000). 
Políticas públicas en torno a los ex Centros Clandestinos de Detención Tortura y Extermino de Argentina: aproximaciones a partir de un estudio de caso

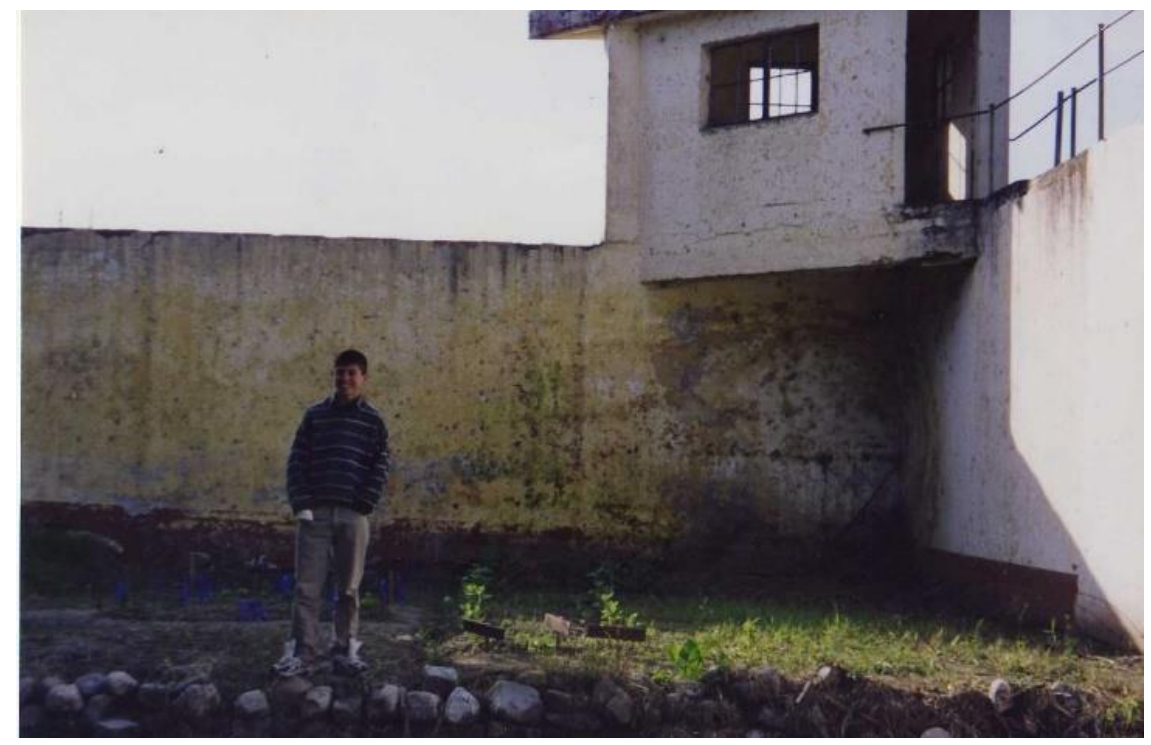

Imagen 3: Alumno del nivel secundario en el proyecto de huerta de la escuela, fondo garita de vigilancia Campo de la Ribera. MOLAS Y MOLAS, 1999.

Fuente: Espacio para la Memoria, Promoción y Defensa de los Derechos Humanos Campo de la Ribera.

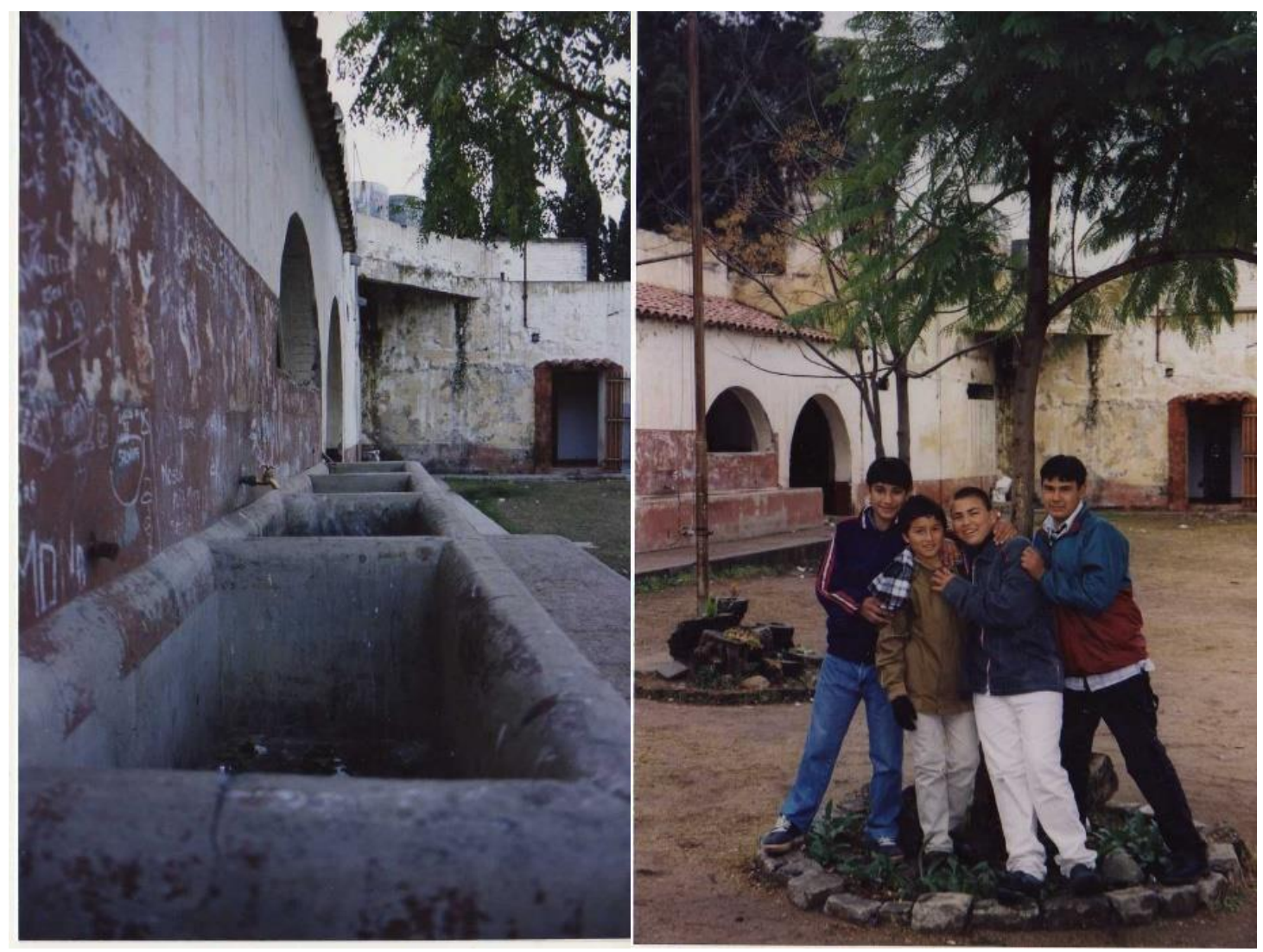

Imagen 4 (Izquierda): Vista de los piletones, al fondo la ventanita indica la presencia de los calabozos. AGUIRRE, 1999. Acervo fotográfico donado por Molas y Molas. Imagen 5 (Derecha): Alumnos pisando plantines y hacia el fondo ventana que comunica con los calabozos. MOLAS Y MOLAS, 1999.

Fuente: Espacio para la Memoria, Promoción y Defensa de los Derechos Humanos Campo de la Ribera. 
Paralelamente a lo que acontencía en la escuela, el sitio de Campo de Ribera volvió a ser tematizado, esta vez por quien fue identificado como el responsable de la primera etapa del funcionamiento del ex CCDTyE. El contexto de impunidad se vivía en el país como definitivo y no como provisorio (FELD, 2016); en ese marco se entiende la publicación de un libro autobiográfico del represor Héctor Vergez en 1995. La publicación de este libro tuvo lugar en la apertura de nuevo ciclo "caliente" de la memoria caracterizado por las declaraciones públicas de varios miembros de las FF.AA. y de Seguridad, que habían actuado en la represión clandestina, y que dieron testimonio en medios masivos de comunicación. ${ }^{23}$ Estas declaraciones no tuvieron por motivación el arrepentimiento, sino más bien su novedad radicó en el reconocimiento público de los represores de hechos denunciados por las víctimas, dando lugar a un resquebrajamiento del "pacto de silencio" que mantenían los perpetradores sobre los desaparecidos, aun cuando no revelaron información nueva ni relevante para conocer el destino de las víctimas (FELD, 2009). En lo que refiere, específicamente, a su desempeño en Córdoba y a Campo de la Ribera en particular, en su libro, Vergez lo presenta como un centro de detención en plena ciudad, que funcionó a la vista de la gente, hasta el advenimiento del 24 de marzo de 1976 (1995:129). "Desde ese lugar hicimos operaciones muy importantes" - continúa su relato- entre las que destacó la operación contra militantes Montoneros entre octubre de 1975 y enero de 1976, con el aval del interventor provincial de ese entonces. Vergez narra en su libro hechos que fueron corroborados luego en los juicios de lesa humanidad, sin embargo, también incluye falsedades y denegaciones notorias de lo ocurrido, sobre todo en lo que refiere a la aplicación de torturas y el destino final de los "detenidos". Cuando reconoce "bajas" y "abatidos" -según su definición- los encuadra en el marco de resistencias, intentos de fugas y/o circunstancias similares que culpabilizan a la víctima por su asesinato. ${ }^{24}$

\footnotetext{
${ }^{23}$ La primera de gran repercusión fue la del ex capitán Adolfo Scilingo reconociendo su participación en los "vuelos de la muerte" en una entrevista con el periodista Horacio Verbitsky y luego en el programa televisivo de Grondona. Para un análisis de la repercusión pública de esta y otras declaraciones puede verse Feld 2009 y 2016.

${ }^{24}$ Salvi (2012) demostró que la retórica de guerra, en la que se inscriben las declaraciones de Vergez, no solo deniega lo sucedido sino que responsabiliza a las víctimas por sus padecimientos.
} 
Durante el mismo año de publicación del libro fue creada en el país la agrupación Hijos por la Identidad y la Justicia contra el Olvido y el Silencio (H.I.J.O.S) que introdujo una nueva práctica de denuncia denominada "escraches". Esta práctica consiste en señalar y evidenciar la identidad de los implicados en las violaciones a los derechos humanos durante la última dictadura militar, quienes estaban en el anonimato, en libertad y gozando de los derechos ciudadanos, bajo el amparo de la impunidad. ${ }^{25}$ Bonafé y Di Toffino (2013), integrantes de H.I.J.O.S, mencionan entre los escraches más importantes, realizados en la provincia de Córdoba fueron sobre el espacio, los represores y los colaboradores del ex CCDTyE La Perla. El sitio de Campo de la Ribera no sería marcado ni escrachado. En ello intervinieron varios factores entre los que se puede nombrar el lugar secundario de Campo de la Ribera en relación a la magnitud represiva de La Perla y su utilización como sede de tres instituciones educativas.

En 1996, el Bachillerato que funcionaba en Campo de la Ribera cambió de nombre y orientación debido a la Ley Provincial de Educación que reformó el sistema educativo, pasó a llamarse “I.P.E.M. N 133 Dr. Florencio de Escardó”. En el año 2000, con fondos provenientes de la Nación y del gobierno Provincial, se realizaron importantes modificaciones al edificio para adaptar lo que fue primero una cárcel y luego un CCDTyE a las necesidades funcionales y de seguridad de una escuela. Esta última importante intervención edilicia consistió en demoler los tres calabozos, la cocina y otros espacios para construir una biblioteca, un laboratorio, un taller y varias aulas. También, demolieron la garita de guardia ubicada en la parte externa del edificio y en oportunidades anteriores habían modificado la puerta de ingreso al edificio, extendido una de las galerías para agregar más aulas y colocaron rejas.

Más allá de esas modificaciones que tuvieron la intención, en el mejor de los casos, de adaptar un mismo espacio a necesidades diferentes y le otorgaban otro valor al trabajo institucional, los alumnos convivieron siempre con algunas huellas de la represión ilegal y el pasado carcelario del lugar, como los piletones que se utilizaron para someter a

\footnotetext{
25 Para un análisis de los aspectos vinculados con la práctica política del "escrache" implementada por H.I.J.O.S puede consultarse los trabajos de Bravo (2012) y de Guarini (2002) quien la entiende como una estética política particular, que empieza a funcionar como paradigma en el lenguaje y la acción, en la construcción de la memoria social.
} 
los detenidos a la "mojarrita", los impactos de bala en las paredes, las garitas policiales, salas de dimensiones pequeñas y los ganchos en la pared lateral del fondo. ${ }^{26}$

\section{La institucionalización de la memoria en los ex CCDTyE}

Tal como se adelantó en la introducción de este artículo, fue a partir de este siglo, luego de la crisis estructural política, económica y social que vivió el país en 2001 y con la llegada de Néstor Kirchner a la presidencia de la nación (2003-2007), cuando tuvo lugar la creación de una política estatal de la memoria que retomó las luchas históricas y demandas de los organismos de derechos humanos y, conjuntamente, impulsaron un proceso de "institucionalización de la memoria" (DA SILVA CATELA, 2010, 2014). Entre las políticas de memoria que gravitan en torno a los espacios y archivos de memoria pueden destacarse la anulación de las leyes del perdón por el Congreso Nacional en 2003 y la refrendación en junio de 2005 por la Corte Suprema de Justicia, la creación del Archivo Nacional de la Memoria (Decreto de Creación 1259/2003), que años después serviría de modelo para la creación de archivos provinciales de memoria, y la desafectación de los usos policiales y militares de predios donde funcionaron CCDTyE para la creación futura de espacios para la memoria y promoción de los derechos humanos. ${ }^{27}$

Además, para la conmemoración de los 30 años del golpe, el presidente autorizó el pleno acceso a los archivos militares de la dictadura y decretó el 24 de marzo feriado nacional inamovible, como el “Día de la Memoria, la Verdad y la Justicia”. Esta fecha pasó a formar parte del caledario escolar, lo cual comprometió a las instituciones educativas a la realización de actos conmemoriativos y motivó el desarrollo de diversos materiales pedagógicos provistos por el Estado para acompañar la tarea docente. También se reeditó el informe Nunca Más, con nuevo prólogo, escrito por Eduardo Duhalde y otros integrantes de la Secretaría de Derechos Humanos de la Nación, orientado a cristalizar la

\footnotetext{
${ }^{26}$ La "mojarrita" es uno de los métodos de tortura que consiste en introducir la cabeza de la persona en líquidos hasta casi asfixiarla.

27 En Lorenzatti y Kraut (2011) puede rastrearse una historización detallada de las acciones llevadas a cabo por los tres poderes del Estado para la reapertura de los juicios a los responsables del terrorismo de Estado. Véase el texto de Bonafé y Di Toffino (2013) para una descripción histórica sobre el devenir de los procesos judiciales por delitos de lesa humanidad en Córdoba desde el retorno de la democracia hasta el año 2012.
} 
perspectiva oficial sobre el sentido del pasado reciente (CRENZEL, 2008; LVOVICH y BISQUET, 2008, p. 89).

También se creó la Red Federal de Sitios de Memoria para articular la gestión de las políticas públicas en los espacios para la memoria de las distintas provincias y municipios. Esta política se vio protegida con la Ley Nacional 26.691 que declaró Sitios de Memoria del Terrorismo de Estado a los lugares que funcionaron como CCDTyE o donde sucedieron hechos aberrantes del accionar de la represión ilegal desarrollada en el país hasta el 10 de diciembre de 1983. Esta ley fue promulgada en julio de 2011 y reglamentada en octubre de 2014 junto a la creación de la Direccion Nacional de Sitios de Memoria, durante los mandatos de Cristina Fernández de Kirchner (2007-2011 y 2011-2015) como presidenta de la nación, en clara continuidad con la política de memoria iniciada en 2003 (decreto 1986/2014). Bajo el último mandato de la presidenta, se declaró “Lugar Histórico Nacional" (decreto 2521/2015) al Espacio para la Memoria Campo de la Ribera -entre otros- con el objeto dar un marco institucional de protección de alcance nacional para los Sitios de Memoria recuperados.

En la provincia de Córdona en 2006, los legisladores aprobaron por unanimidad la Ley 9286, denominada "Ley de la Memoria", producto de la presión ejercida por los organismos de derechos humanos a nivel local y del consenso alcanzado en sectores más amplios. La ley estableció la creación de la Comisión y el Archivo Provincial de la Memoria con plena autonomía funcional y económica, en el marco del Ministerio de Justicia y Derechos Humanos de Córdoba. ${ }^{28}$ En lo que refiere a los espacios para la memoria, la Ley no declara un contenido específico o museográfico. Tampoco, alude a la "recuperación" de otros sitios que funcionaron como CCD en la provincia para su funcionamiento como espacios para la memoria. Se recuerda que recién cinco años después se dictaría la ley nacional 26.691 que declaraba a los ex CCD espacios para la memoria. En este sentido, la recuperación de los ex CCDTyE de D2, La Perla y Campo de la Ribera -los tres sitios de

\footnotetext{
${ }^{28}$ La Comisión Provincial de la Memoria está integrada por representantes de los Organismos de Derechos Humanos de Córdoba con reconocida trayectoria en la preservación de la memoria de las violaciones a los derechos humanos por parte del terrorismo de Estado (Abuelas de Plaza de Mayo, Familiares de Desaparecidos y Detenidos por Razones Políticas, H.I.J.O.S., Asociación de Ex Presos Políticos y el Servicio de Paz y Justicia), de la Universidad Nacional de Córdoba, de los poderes Ejecutivo, Legislativo y Judicial y del movimiento obrero cordobés.
} 
memoria de la provincia de Córdoba- fueron experiencias anteriores a la existencia de la ley nacional que se construyeron al calor de las coyunturas políticas, retomando discusiones que habían tenido lugar en otros sitios como en la ex ESMA y los reclamos históricos de los organismos, y priorizando la magnitud de la represión que tuvo lugar en esos sitios y la centralidad en la red clandestina.

\section{Campo de la Ribera de escuela a Espacio para la Memoria, Promoción y Defensa de los Derechos Humanos}

A metros de distancia de Campo la Ribera, durante 2002-2003, el Equipo Argentino de Antropología Forense (EAAF) realizaba nuevas excavaciones arqueológicas en el Cementerio San Vicente en el marco de la causa "Averiguación de Enterramientos Clandestinos" que se tramitaba como Juicio de la Verdad Histórica en el Juzgado Federal $\mathrm{N}^{\circ} 3$, a cargo de la jueza Cristina Garzón de Lascano. Los principales resultados fueron el análisis de ciento noventa y tres esqueletos y, hasta 2008, la identificación y restitución a sus familias de los restos de trece personas que se encontraban desaparecidas. ${ }^{29} \mathrm{El}$ trabajo del EAAF tuvo una importante repercusión entre los vecinos de los barrios colindantes -sus recuerdos sobre aquello que vieron en los ' 70 adquirieron dimensiones públicas y fueron legitimados sus conocimientos-y también en la prensa local que publicó durante el 2003 numerosos artículos relacionados con los hallazgos y declaraciones de los familiares directos de las víctimas identificadas.

Simultáneamente a las investigaciones del EAAF y al cambio en el tratamiento de las violaciones a los derechos humanos tras la asunción de la presidencia por Néstor Kirchner en el año 2003, tuvo lugar el cambio de las autoridades de la escuela secundaria alojada en Campo de la Ribera y con eso comenzó un proceso de apertura hacia la comunidad y de reconocimiento de la historia del sitio. En pos de esto, la nueva directora -María Elena Verra- entabló vínculos con la Red Social de la $5^{a}$, organización que nucleaba a varias instituciones y organizaciones de la zona, con el objetivo de mejorar la calidad de vida de esa porción de la ciudad.

\footnotetext{
29 Para ver en detalle el proceso de investigación, la metodología utilizada, los resultados completos del Informe del EAAF consultar Olmos (2005) y para una síntesis bien lograda ver Olmo y Salado Puerto (2008).
} 
El acercamiento de las instituciones que conformaban la Red Social de la $5^{\mathrm{a}}$ a Campo de la Ribera, algunas representadas por mujeres vecinas y madres de los jóvenes que asistían allí al secundario, inició un proceso colectivo de conocimiento de la historia de la represión, a veces contada por los mismos alumnos a partir de lo que veían o escuchaban, y gestó la idea de solicitar al gobierno de la provincia de Córdoba un edificio nuevo. En ese entonces, hacia finales de 2003, no se pensaba a Campo de la Ribera como espacio para la memoria, sino que se comenzó a pensar la posibilidad de edificios nuevos para jerarquizar y dignificar la educación y la comunidad que allí asistía. Sin embargo, la posibilidad de trasladar el secundario encontró resistencias en el gobierno provincial y, también, en una parte de la propia comunidad educativa que no quería dejar ese espacio.

El personal de la institución y parte del estudiantado habían naturalizado las condiciones en las que se desarrollaba el dictado de las clases. Los esfuerzos invertidos para acondicionar el espacio y las modificaciones edilicias recientes habían generado sentimientos de pertenencia y apego.

En miras de la decisión institucional de integrar la historia de la represión que conjuga el edificio y lograr la apertura institucional hacia las comunidades barriales colindantes, en octubre de 2003 , la Red Social de la $5^{\text {a }}$ organizó su feria anual en las instalaciones de la escuela. Allí, se presentó la obra colectiva "El infierno sepultado busca vida en el presente", producida y actuada por un grupo de quince estudiantes que representó los horrores sufridos por las víctimas alojadas en Campo de la Ribera. El guion de la obra se había nutrido de los relatos sobre Campo de la Ribera transmitidos por los familiares de los alumnos participantes y estaba estructurado en seis escenas que teatralizaban las torturas, violaciones y fusilamientos. Así, mientras se abría la circulación de memorias de la represión, simultáneamente, en el ámbito de la escuela, ciertos docentes bregaban por clausurar la emergencia del pasado. Una alumna recuerda que:

Allá al fondo, en la pared, hay ganchos. Y le pusimos a preguntar a los profesores, y justo encontramos a una y nos dijo: 'es mejor no saber qué era eso, y no remover las cosas del pasado'... es como que nos ocultan las cosas así, es como que no le gusta contar las cosas (Alumna de $2^{\circ}$ " $\mathrm{C}$ " en CRISTORI, GUEVARA, PONTILIANO Y ABRAHAM, 2004). 
Al año siguiente se conmemoró por primera vez el 24 de marzo de 1976 con la participación de alumnos y sus padres, vecinos, la Red Social de la $5^{\mathrm{a}}$ y de los organismos de derechos humanos. Las escuelas participaron con canciones y representaciones "La Memoria" y "Si estas paredes hablarán". Por primera vez, ex presos políticos que estuvieron secuestrados en Campo de la Ribera relataron, en ese lugar, las memorias de sus experiencias.

En el marco de estas acciones la dirección de la escuela, junto a la Red Social de la $5^{\mathrm{a}}$, promovió diferentes actividades a cargo del EAAF, H.I.J.O.S y la Universidad Nacional de Córdoba que permitieron resignificar y reconstruir la memoria de la zona vinculada con el terrorismo de Estado. Algunas se desarrollaron en la escuela y otras en espacios institucionales diferentes. También, ex presos políticos de Campo de la Ribera se acercaron cada vez con más frecuencia para reconocer el lugar, identificar las modificaciones y relatar el funcionamiento del ex CCD. Así, la existencia de la escuela en el ex CCD y la historia de represión traspasaron los muros de la escuela, se instalaron en otros ámbitos e involucraron a nuevos actores.

De manera creciente, las madres y los padres de los alumnos y otros actores de las comunidades aledañas comenzaron a considerar a Campo de la Ribera inapropiado para el funcionamiento de escuelas y la solicitud de un edificio nuevo ganó adhesión. A la vez, el contexto general se había modificado: se recuerda que simultáneamente se dictó la Ley Provincial de la Memoria en 2006, se produjo el desalojo de los militares de La Perla y su traspasó a la Comisión Provincial de la Memoria (APM) en 2007 para su apertura como espacio de memoria, experiencias similares se sucedieron otras ciudades y creció y legitimó el reclamo de los organismos de "recuperar" los sitios que habían funcionado como ex CCDTyE. A partir de aquí, los representantes de los organismos de derechos humanos y de la CPM se integraron a las reuniones semanales de la Red Social de la $5^{a}$, espacio consolidado de discusión y trabajo en Campo de la Ribera, y algunos comenzaron a pensar en Campo de la Ribera como espacio para la memoria, mientras que otros además de aceptar que fuese un espacio de memoria- proponían mantenerlo como un espacio educativo y, también, de esparcimiento de los vecinos de la zona. 
Ante la falta de respuesta del Ministerio provincial a la demandas de nuevos edificios, en agosto del año 2008, las madres de los alumnos "tomaron" el establecimiento donde funcionaba la escuela secundaria con la participación activa de los organismos de derechos humanos y la Red de la $5^{\text {a }}$, con el lema "Por nuestro derecho a la educación; por nuestro derecho a la memoria". ${ }^{30}$ En esa oportunidad, se entregó un petitorio a representantes de las Secretarías de Derechos Humanos y de Educación de la Nación que exigía las nuevas instalaciones acompañado por un documento con 824 firmas de padres y vecinos apoyando el reclamo. Ese petitorio tenía tres ejes:

1) Las escuelas no funcionaban en edificios apropiados para la función educativa (...) y que por ende se reclamaban edificios nuevos para las escuelas. 2) Por una cuestión de historia estos nuevos edificios debían mantener un lazo con el Campo de la Ribera. 3) El espacio del Campo de la Ribera debía quedar como un Sitio de Memoria y que en ese sitio se trabajara desde lo social con talleres recreativos y culturales (CHRETIEN, integrante de la Red Social de la $5^{a}$, marzo de 2013). ${ }^{31}$

El gobierno nacional vehiculizó el pedido y se decidió la construcción de las nuevas escuelas. El gobierno provincial se ocupó de la edificación de la escuela secundaria y el nacional del jardín de infantes y la escuela primaria. La localización de los mismos se estableció a escasos 200 metros (aproximadamente) de los viejos edificios, en el ex predio militar de Campo de la Ribera. Recién en mayo de 2009 quedó inaugurado el nivel secundario en el nuevo edificio y en noviembre año 2010 trasladaron los niveles inicial y primario.

Durante los meses que el edificio del ex CCDTyE estuvo deshabitado, vecinos de la zona saquearon sanitarios, bachas, bancos, rejas, etc., y circulaba el rumor de su posible

\footnotetext{
30 Según los testimonios de integrantes de la Red Social de la $5^{\text {a }}$ y referentes sociales de la zona, la tarea y el compromiso de las madres fueron fundamentales para lograr el traslado de las escuelas a nuevos edificios. Las modalidades de reclamo iban desde la toma de las escuelas hasta la presencia de ellas en todo evento y acto político que se realizaban en la zona. Los organismos de derechos humanos que tuvieron mayor participación en los reclamos en Campo de la Ribera fueron la Asociación de Ex Presos Políticos de Córdoba e H.I.J.O.S. Sobre la historia de estas organizaciones puede consultarse https://sites.google.com/site/expresospoliticoscordoba/home y Bravo (2012) respectivamente.

${ }^{31}$ Este petitorio se elaboró a principios de 2006, teniendo en cuenta los aportes de los padres y referentes de instituciones de la zona. El consenso en los puntos centrales del petitorio es producto del proceso descripto en las páginas anteriores y tiene que ver principalmente con el reconocimiento y la resignificación de la historia de represión acontecida en el sitio y de un conjunto de políticas a nivel nacional y provincial que habilitaban a pensar en los ex CCDTyE como sitios de memoria.
} 
ocupación por familias con necesidades habitacionales no resueltas. A raíz de ello, una delegación reducida de la Agrupación de ex Presos Políticos de la ciudad de Córdoba decidió habitar, durante las horas del día, el edificio de mayor valor simbólico en la rememoración de los hechos de violencia política para evitar robos, destrucciones y su ocupación y, en consecuencia, el alto costo político que hubiera significado desalojar esas familias.

El edificio tenía los mismos problemas que la escuela había denunciado años antes, pero agravados. Aun así, y sin un proyecto de actividad definido, aquel grupo de ex Presos Políticos asistió todos los días al lugar, no realizaban otra actividad o tarea más que permanecer y mostrar la ocupación del espacio. Se dijeron, "vamos y ocupamos, y después vemos cómo avanzamos" (PAREDES, Director del Espacio para la Memoria Campo de la Ribera, en marzo de 2013). Consideramos esa práctica una de las marcaciones iniciales del sitio de memoria, en diálogo con las lógicas del territorio urbano-marginal en el que está inserto. En la acción de proteger el lugar de cautiverio, los ex presos políticos se apropian del sitio para evitar su apropiación. ${ }^{32}$

Las negociaciones y las discusiones en los orígenes de Campo de la Ribera como Espacio para la Memoria fueron muchas. Las características y necesidades de la zona y la compleja trama de actores involucrados en la recuperación del lugar como sitio de memoria -la Red Social de la $5^{\mathrm{a}}$, padres de los alumnos que cursaban en las escuelas y vecinos, miembros de los Organismos de Derechos Humanos y la CPM- amplió las disputas sobre el destino final, usos y perfil que debían tener los edificios de Campo de la Ribera. A partir de las entrevistas realizadas a referentes de cada uno de los grupos, se podrían identificar y esquematizar algunos de los problemas que atravesó la conformación del sitio de memoria. En los momentos previos al traslado de las instituciones educativas a los nuevos edificios las disputas giraron en torno a los nuevos

\footnotetext{
32 Ciertas prácticas comprendidas en aquello que llamamos de modo muy general "lógica territorial" guardan relación con la historia de conformación de ciertos sectores de la zona ligados con la ocupación de terrenos fiscales, viejas casas y/o las barrancas (GARBERO, 2014). Por ejemplo, los orígenes de las comunidades de Bajada San José (según la división catastral pertenece al barrio Maldonado pero los vecinos realizan la división nominal), parte de Villa Inés y de la barrancas de Maldonado estuvieron relacionados con la toma de tierras y organización de asentamientos. El predio de Campo de la Ribera podría no haber sido la excepción y para muchos representaba solo un lugar, como otros, posible para habitar.
} 
usos que tendrían los edificios de Campo de la Ribera, a la apropiación y reconocimiento de los actores en el proceso largo de lucha y en los protagonismos de las victorias y fracasos, falta de claridad de los intereses de los actores principales y pugnas de poder con personalidades que no habían participado -externos a los actores antes nombrados-, pero que también tenían intereses de ocupar el lugar para fines muy diferentes a los que estaban presentes en la discusión principal.

En la transición de apertura del Espacio para la Memoria, las discusiones se centraron en la escasez de diálogo entre los actores en la última etapa del proceso desde el 2009 hasta que, finalmente, se inauguró el sitio en el 2010, la distribución de los cargos públicos, los objetivos finales que se fijaron para el sitio, y la asignación de un presupuesto reducido para la inauguración como Espacio de Memoria.

Este derrotero tuvo algunas definiciones cuando el 24 de marzo de 2010 Campo de la Ribera abrió sus puertas como "Espacio para la Memoria, Promoción y Defensa de los Derechos Humanos". 33 Durante los meses anteriores, Mario Paredes -ex preso político secuestrado en enero de 1976 durante alrededor de 8 años, en distintas dependencias carcelarias y CCD del país y miembro de la comisión directiva de la Asociación de Ex Presos de Córdoba- fue designado por la CPM como director y estuvo encargado de la redacción del proyecto que articuló las diferentes propuestas presentadas, entre las que se destaca la elaborada por la Red Social de la $5^{\text {a }}$ en conjunto con las madres y los padres que lucharon por los nuevos edificios. Las particularidades del proyecto fundador del Espacio para la Memoria de Campo de la Ribera son la reiterada mención al lazo entre el sitio y la comunidad, el postulado de incluir las memorias sobre la represión desde los testimonios de los sobrevivientes y las memorias de la comunidad educativa y la comunidad en general, y el énfasis en el desarrollo de diferentes proyectos comunitarios que estuvieran relacionados con la promoción y defensa de los derechos humanos en un sentido amplio.

El proyecto articula como propósitos la construcción de un sitio de memoria a partir de las marcas y las señales existentes en el edificio que fue sede del ex CCDTyE, su

33 El Ministerio de Educación otorgó, mediante resolución 124/2009, el ejercicio de la tenencia precaria de este inmueble a la Secretaría de Derechos Humanos (Información brindada por Delia Galará, área de investigación del Espacio para la Memoria de Campo de la Ribera). 
preservación edilicia, la representación de lo acontecido durante el terrorismo de Estado y las luchas pasadas y recientes y la creación de un espacio de reflexión y duelo. Para los otros dos edificios, propone el desarrollo de diferentes proyectos comunitarios que estén relacionados con la promoción y defensa de los derechos humanos en un sentido amplio, vinculados con el pasado y el presente.

\section{A modo de cierre}

El articuló recorrió casi treinta años de políticas públicas y de discusión entre los actores que participan de los organismos de derechos humanos y el Estado para explicar proceso de lucha social, política y simbólica por el cual los mismos lugares que funcionaron como centros clandestinos de detención, tortura y exterminio se erigieron como espacios para la memoria y la promoción de los derechos humanos. En este sentido, el estudio del caso mostró que al regreso de la democracia, Campo de la Ribera se constituyó en la prueba jurídica de las denuncias de las víctimas. Luego, en el contexto caracterizado por la impunidad y por una narrativa oficial de reconciliación y olvido, Campo de la Ribera no solo no sería escrachado ni marcado como ex CCDTyE, sino que el gobierno provincial lo destinaría como sede de instituciones educativas. La historia del edificio sería doblemente silenciada por decisión de la dirección de la institución, cuestión que tendría su primer quiebre en el año 2003 con la llegada de una nueva directora que inició un proceso de apertura y reconocimiento de la historia del sitio y el hallazgo de una de las mayores fosas comunes relacionadas con la práctica del terrorismo de Estado en el cementerio colindante gracias al trabajo del EAAF. Estos acontecimientos tuvieron lugar en un nuevo contexto caracterizado por el cambio del tratamiento de las violaciones a los derechos humanos y el desarrollo de una política de memoria. El singular proceso de “recuperación” del Campo de la Ribera como Espacio para la Memoria, Promoción y Defensa de los Derechos Humanos estuvo caracterizado por un conjunto de acciones, disputas y discusiones entre una amplia variedad de actores -no solo organismos de derechos humanos o la Comisión Provincial de la Memoria- con distintas trayectorias e intereses. Finalmente, en la intersección de la tríada memoria, espacio e identidad que se materializaron en las construcciones memoriales, Campo de la Ribera resaltó la dimensión 
de promoción de derechos en diálogo directo con el entorno en el que está inserto y la preservación del patrimonio edilicio para la (re)presentación de lo acontecido durante el terrorismo de Estado, a partir del testimonio de las víctimas -lo cual obliga considerar la represión previa a 1976-, y las huellas de las políticas de olvido e impunidad que, aún en democracia, constituyen la historia larga de sus edificios.

\section{Referencias}

AGUIRRE, L. Piletones de Campo de la Ribera. 1999, 1 foto, color, $12 \mathrm{~cm}$ x $10 \mathrm{~cm}$. Acervo fotográfico donado por María Molas y Molas al Espacio para la Memoria, Promoción y Defensa de los Derechos Humanos Campo de la Ribera.

ALEJANDRA. Alejandra: entrevista [ag. 2013]. Entrevistadora: Vanesa Garbero. Córdoba, 2013. Entrevista concedida para la realización de un trabajo académico.

ALONSO, Luciano. El surgimiento del movimiento argentino por los Derechos Humanos en perspectiva comparada. Páginas, Rosario, v. 1, n. 1, p. 87 -109. 2008.

ALONSO, Luciano. Las luchas pro derechos humanos en Argentina: de la resistencia antidictatorial a la dispersión del movimiento social. In: Mara Burkart y Matías Giletta (Coord.) Dossier Argentina: 30 años de democracia. Buenos Aires: Instituto de Estudios de América Latina y el Caribe. 2013, p. 104-120.

ALONSO, Luciano. Redes y dimensiones espaciales en la movilización por los derechos humanos en Argentina. Avances del Cesor, Rosario, v. 13, n. 12, p. 117 - 139. 2015.

BESSE, Juan; ESCOLAR, Cora. Política y memoria, semblanza de una relación indócil. Diálogos, Revista do Departamento de História e do Programa de Pós-Graduação em História, Maringá, v. 16, n. 3, p. 897 - 924. 2012.

BONAFÉ, Lucía; DI TOFFINO, Silvia. Recorrido histórico de las causas por delitos de lesa humanidad en la provincia de Córdoba. In: AA.VV. Informe provincial 2013: mirar tras los muros: situación de los derechos humanos de las personas privadas de libertad en Córdoba. Córdoba: Archivo Provincial de la Memoria, 2013, cap. 1, p.1-29. 
BRAVO, Nazareno. H.I.J.O.S. en Argentina. La emergencia de prácticas y discursos en la lucha por la memoria, la verdad y la justicia. Sociológica [en linea], v. 27, n. 76, p. 231-248. 2012.

\section{C.A.D.H.U. Informe especial sobre el Campo de Concentración de detenidos-} desaparecidos de "La Perla" en Córdoba, república Argentina. Madrid: C.A.D.H.U, 1980.

CHRETIEN, Marcia. Marcia Chretien: entrevista [mar. 2013]. Entrevistadora: Vanesa Garbero. Córdoba, 2013. Entrevista concedida para la realización de un trabajo académico.

CONADEP. Colección Campo de la Ribera. 1984. 2 fotos, blanco y negro, $12 \mathrm{~cm} \times 10 \mathrm{~cm}$. Fuente Espacio para la Memoria, Promoción y Defensa de los Derechos Humanos Campo de la Ribera.

CONADEP. Informe de la Comisión Nacional sobre la Desaparición de Personas, delegación Córdoba. Córdoba: Familiares de desaparecidos y detenidos por razones políticas de Córdoba, 1999.

CONADEP. Nunca más Informe de la Comisión Nacional sobre la Desaparición de Personas. 5. ed. Buenos Aires: Eudeba, 1984.

CONTEPOMI, Gustavo; ASTELARRA, Patricia. Sobrevivientes de La Perla. Córdoba: El Cid Editor, 1984.

CRENZEL, Emilio. Cartas a Videla: una exploración sobre el miedo, el terror y la memoria. Telar, Tucumán, v. 2, n. 2 y 3, p. 41-57. 2005.

CRENZEL, Emilio. La historia política del Nunca Más: la memoria de las desapariciones en la Argentina. Buenos Aires: Siglo XXI, 2008.

CRENZEL, Emilio. Verdad, justicia y memoria. La experiencia argentina ante las violaciones a los derechos humanos de los años setenta revistada. Telar, Tucumán, n. 13-14, p. 50 - 66. 2015.

CRISTORI, Anabela; GUEVARA, Verónica; PONTILIANO, Carla; ABRAHAM, Sergio (Prod.). Huellas: Campo de la Ribera [Película]. Córdoba: Escuela de Ciencias de la Información, Universidad Nacional de Córdoba, 2004. Disponible para su consulta en el Archivo Provincial de la Memoria de Córdoba.

DA SILVA CATELA, Ludmila. "Lo que merece ser recordado..." conflictos y tensiones en torno a los proyectos públicos sobre usos del pasado en los sitios de memoria. Clepsidra, Buenos Aires, n. 2, p. 28-47. 2014.

DA SILVA CATELA, Ludmila. Exponer lo invisible. Una etnografía sobre la transformación de Centros Clandestinos de Detención en Sitios de Memoria en Córdoba-Argentina. In: 
MEDALLA, Tania; PEIRANO, Alondra; RUIZ, Olga ; WALCH, Regine(Eds.). Recordar para pensar Memoria para la Democracia. La elaboración del pasado reciente en el Cono Sur de América Latina. Buenos Aires: Ediciones Böll Cono Sur, 2010, p. 44-56.

DA SILVA CATELA, Ludmila. Pasados en conflicto. De memorias dominantes, subterráneas y denegadas. In: BOHOSLAVSKY, Ernesto; FRANCO Mariana; IGLESIAS, Mariana; LVOVICH, Daniel. Problemas de historia reciente del Cono Sur. Volumen I. Buenos Aires: Prometeo Libros, 2010, p. 99-123.

FELD, Claudia. El imposible debate entre víctimas y victimarios: notas sobre las declaraciones televisivas de Miguel Etchecolatz (1997). Rubrica Contemporanea, Barcelona, v. 5, n. 9, p. 77-101. 2016.

FELD, Claudia. Entre la visibilidad y la justicia: los testimonios televisivos de represores en la Argentina. Encuentros Uruguayos, Montevideo, n. 2, p. 42-57. 2009.

FELD, Claudia. Prólogo. La memoria en su territorio. In: WALTER, Jacques; FLEURY, Béatrice (Comps.). Memorias de la piedra:ensayos en torno a lugares de detención y masacre. Buenos Aires: Ejercitar la Memoria Editores, 2011, p. 9-17.

GALARÁ, Delia. Delia Galará: entrevista [oct. 2013]. Entrevistadora: Vanesa Garbero. Córdoba, 2013. Entrevista concedida para la realización de un trabajo académico.

GALARÁ, Delia. Delia Galará: entrevista [abr. 2015]. Entrevistadora: Vanesa Garbero. Córdoba, 2015. Entrevista concedida para la realización de un trabajo académico.

GARBERO, Vanesa. Memorias del Terrorismo de Estado en los barrios aledaños al ex Centro Clandestino de Detención Tortura y Exterminio Campo de la Ribera y Cementerio San Vicente - Córdoba. 2014. Tesis de Maestría en Sociología no publicada (Maestría)Centro de Estudios Avanzados, Universidad Nacional de Córdoba, Córdoba, 2014.

GASTÓN. Gastón: entrevista [sep. 2012]. Entrevistadora: Vanesa Garbero. Córdoba, 2012. Entrevista concedida para la realización de un trabajo académico.

GUARINI, Carmen. Memoria social e imagen. Cuadernos de Antropología Social, n.15, p. 113-123. 2002.

GUGLIELMUCCI, Ana. La consagración de la memoria: una etnografía acerca de la institucionalización del recuerdo sobre los crímenes del terrorismo de Estado en la Argentina. Buenos Aires: Antropofagia, 2013.

JELIN, Elizabeth. La política de la memoria: el movimiento de derechos humanos y la construcción democrática en la Argentina. In: ACUÑA, Carlos et al. Juicio, castigo y memorias: derechos humanos y justicia en la política. Buenos Aires: Nueva visión, 1995, p. $101-146$. 
JELIN, Elizabeth; AZCÁRATE, Pablo. Memoria y política: Movimiento de Derechos Humanos y construcción democrática. América Latina Hoy, n. 1, p. 29 - 38. 1991.

LEIS, Héctor. El movimiento de derechos humanos y la política Argentina. Buenos Aires: Centro Editor de América Latina, 1989.

LORENZETTI, Ricardo; KRAUT, Alfedro. Derechos humanos: justicia y reparación:la experiencia de los juicios en la Argentina: Crímenes de lesa humanidad. Buenos Aires: Sudamericana, 2011.

LVOVICH, Daniel; BISQUET, Jaquelina. La cambiante memoria de la dictadura: discursos públicos, movimientos sociales y legitimidad democrática. Los Polvorines: Univ. Nacional de General Sarmiento. Buenos Aires: Biblioteca Nacional, 2008.

MARCHETTI, Florencia; MOLAS Y MOLAS, María. Comunidad y memorias locales. Congreso de Argentino de Antropología Social,7. Villa Giardino, Córdoba, 2004.

MOLAS Y MOLAS, María. Campo La Ribera, diez años después: un punto de referencia, un espacio disputado. In: CATELA, Ludmila Da Silva; GIORDANO, Mariana; JELIN, Elizabeth (Eds.). Fotografías e identidad: captura por la cámara, devolución por la memoria. Buenos Aires: Nueva Trilce, 2010, p. 105-129.

MOLAS Y MOLAS, María. De un centro clandestino de detención a un espacio para la educación:historia y singularidad de la Escuela FE. Trabajo de conclusión de curso (graduación) - Facultad de Psicología. Córdoba: Universidad Nacional de Córdoba, 2000.

MOLAS Y MOLAS, M. Escuela en Campo de la Ribera. 1999. 2 fotos, color, $12 \mathrm{~cm} \mathrm{x} 10 \mathrm{~cm}$. Acervo fotográfico donado por la María Molas y Molas al Espacio para la Memoria, Promoción y Defensa de los Derechos Humanos Campo de la Ribera

MOLAS Y MOLAS, María; LEMME, Daniel Miguel. De un centro clandestino de detención a un espacio para la educación. Notas sobre la escuela en Campo de la Ribera. Cuadernos de Educación, Córdoba, 2, n. 2, p. 211-225, 2002.

OLMO, Dario (Comp.). Cementerio de San Vicente: informe 2003. Córdoba: Ferreyra Editor, 2005.

OLMO, Darío; SALADO PUERTO, Mercedes. Una fosa común en el interior de Argentina: el Cementerio de San Vicente. Revista del Museo de Antropología (RAM), Córdoba, 1, n. 1, p. $3-12.2008$.

PAIARO, Melisa. Acción conjunta. Las actuaciones del Tercer Cuerpo y del D2 antes del golpe de 1976 en Córdoba. Diario de la Memoria, V , n. 6, p. 26 - 27. 2012. 
PALMAS ZALDUA, Luz; TORRAS, Verónica; HOURCADE, Sol; BLANCHARD, Sebastián; GRIFFA, Tomás. Las políticas de memoria, verdad y justicia a cuarenta años del golpe. In: CELS - Centro de Estudios Legales y Sociales. Derechos humanos en la argentina: Informe 2016. Buenos Aires: Siglo veintiuno editores, 2016, p. 25 - 56.

PAREDES, Mario. Mario Paredes: entrevista [mar.2013]. Entrevistadora: Vanesa Garbero. Córdoba, 2013. Entrevista concedida para la realización de un trabajo académico.

RÉBORA, Luis Armando. Testimonio. Diario del Juicio, Buenos Aires, Editorial Perfil S.A, V.1, n. 13, 20 ago. 1985. p. 292-296.

REYNA, Roberto. La Perla. Córdoba: El Cid Editor, 1984.

ROBLES, Miguel. La búsqueda. Una entrevista con Charlie Moore. Córdoba: Ediciones del Pasaje, 2010.

SALVI, Valentina. De vencedores a víctimas: memorias militares sobre el pasado reciente en la Argentina. Buenos Aires: Biblos, 2012.

SERVETTO, Alicia. Córdoba en los prolegómenos de la dictadura. La política del miedo en el gobierno de Lacabanne. Estudios, Córdoba, n. 15, p. 143 - 156, 2004.

SIKKINK, Kathryn. The emergence, evolution, and effectiveness of the Latin American human rights network. In: JELIN, Elizabeth; HERSHBERG, Eric. Constructing democracy: human rights, citizenship, and society in Latin America. Boulder: Westview Press, 1996, p. 59 - 84.

SOLIS, Ana Carol. La cuestión de los derechos humanos: de la posdictadura a la democracia excluyente (Córdoba, 1989-2002). In: GORDILLO, Mónica, ARRIAGA, Ana; FRANCO, María; MEDINA, Leticia; NATALUCCI, Ana; SOLIS, Ana Carol. La protesta frente a las reformas neoliberales en la Córdoba de fin de siglo. Córdoba: Ferreyra Editor, 2012, p. 307- 400 .

SOLIS, Ana Carol. De las comisiones a los organismos en Córdoba: derechos humanos, dictadura y democratización. In: KOTLER, Rubén (Coord.). En el país del sí me acuerdo: los orígenes nacionales y transnacionales del movimiento de derechos humanos en Argentina: de la dictadura a la transición. Buenos Aires: Imago Mundi y Red Latinoamericana de Historia Oral, 2014, p. 129 - 156.

SUZZARA, Cecilia. Testimonio. Diario del Juicio, Buenos Aires, Editorial Perfil S.A, v.12, 13 ago. 1985. p. 266-268. 
TELLO, Mariana. "Yo acuso": un análisis antropológico sobre lo jurídico en los
testimonios acerca de La Perla. Clepsidra, Buenos Aires, n. 4, p. 90 - 115. 2015.

VERBITSKY, Horacio. Regalo de Nochebuena. Página 12, 24 de diciembre de 1998.

Disponible en: HYPERLINK "http://www.pagina12.com.ar/1998/98-12/98-1224/pag09.htm". Acceso en: 10 de junio de 2019.

VERGÉZ, Hector. Yo fui Vargas: el antiterrorismo por dentro. Buenos Aires: Edición del Autor, 1995 